\title{
The effects of variations in confirmation training on discrimination performance'
}

\section{SUE SEITZ, Austin State School, Austin, Tex. 78767}

Variations within the training procedure of Confirmation were examined to determine their effect on performance of a discrimination task. Performance was significantly improved by elimination of interspersed test trials. Results suggest a reconsideration of the comparability of prompting and confirmation as alternative training procedures.

Hawker (1967) observes that variations within the training procedures of prompting and confirmation may account for differences in results reported (Cook, 1958; Cook \& Spitzer, 1960; Hawker, 1964, 1965, 1966). Particularly, procedures become important when training is also constrained by the use of an automated teaching device. Here, the $S$ must press a lever to indicate a response. Only a correct response will advance the program in practice trials, but any response will advance the program in test trials. One procedural difference in prompting and confirmation is seen in the discriminability of test and practice trials. In practice trials in the prompting condition, the correct word is always indicated. In confirmation, however, test trials look like practice trials. Since any response on a test trial advances the program, this may be interpreted by the $S$ as indicating a correct response, resulting in the formation of incorrect associations. This experiment was directed toward determining if by making confirmation test trials more distinguishable, or by eliminating tests as separate trials, performance under this condition could be improved.

\section{SUBJECTS}

Twenty-four retardates at the Austin State School served as Ss in this experiment. Eight Ss were randomly assigned to each of the three experimental conditions. Analysis of variance indicated that the groups did not differ significantly in IQ or chronological age (see Table 1).

\section{APPARATUS}

The MTA SR-400 Scholar, an automated machine which enables the $S$ to advance a printed program, was used to present the list of paired stimuli. The eight pairs of pictures were: table, gun; dog, lock; flower, cow; man, kite; pan, monkey; sock, balloon; car, rake; and airplane, shirt. All materials were randomized for order of presentation in the list and for position.

For Condition 1, the procedure followed that used by Hawker (1966) in his discrimination studies: Eight pairs of pictures were presented for a practice trial, then these eight pairs were presented in a different order and position for a test trial. The $S$ was required to learn that one member of each pair was the "correct" response. Twenty test trials were interspersed with 20 practice trials. The performance was $S$-paced in that the $S$ 's responses advanced the program. The $S$ was told that when he had made a correct choice the paper would move forward.

Table 1

Means and SDs of the Chronological Age and IQ of the Three Groups of Eight Educable Mentally Retarded Ss. There were No Significant Differences between the Groups for either Age or IQ (F $<1)$

\begin{tabular}{ccrcr}
\hline Condition & \multicolumn{3}{c}{ Age } & \multicolumn{2}{c}{ IQ } \\
& Mean & SD & Mean & SD \\
1 & 13.29 & 2.05 & 59.29 & 6.62 \\
2 & 13.75 & .71 & 61.50 & 9.56 \\
3 & 12.50 & 2.44 & 54.88 & 9.52 \\
\hline
\end{tabular}

Table 2

Means and Standard Deviations of Error Scores in Three Confirmation Conditions for the First and Last Five Blocks of Trials

\begin{tabular}{cccc}
\hline Group & & Block I & Block II \\
\hline 1 & Mean & 13.88 & 13.25 \\
& SD & 4.70 & 7.79 \\
2 & Mean & 16.62 & 15.38 \\
& SD & 5.04 & 7.38 \\
3 & Mean & 13.50 & 4.50 \\
& SD & 4.50 & 4.10 \\
\hline
\end{tabular}

In Condition 2, reinforcement in addition to program advancement was provided by the $E$ on all practice trials. As in Condition 1, the machine automatically advanced the program to the next pair of pictures when the $S$ made a correct response on a practice trial. In addition, the $E$ rewarded the $S$ with an M \& M and said "that's right," but only when the S's first choice was the correct one. Again. during the test trials, the $E$ offered no reinforcement, and the machine advanced the program after each response.

In Condition 3 , the $E$ advanced the program with a remote control after each correct response and rewarded the $S$ with an $M \& M$ and "that's right." In this condition, 20 practice trials also served as test trials, and correct responses were recorded whenever the S's first choice was correct.

\section{RESULTS AND DISCUSSION}

Inspection of the means and standard deviations of error scores indicated that the assumption of homogeneity of variance had not been met (Table 2). Raw scores we re transformed to $\log (\mathrm{x}+1)$ (Edwards, 1964, p. 130). An analysis of variance over blocks of the first and last five trials showed the only significant source of variance to be between Groups $(\mathrm{F}=5.63, \mathrm{df}=2 / 21, \mathrm{p}<.05)$. An orthogonol comparison of Groups 1 and 2 with Group 3 showed fewer errors for Group $3(F=10.09, \mathrm{df}=1 / 21, \mathrm{p}<.01)$. There was no significant difference between Groups 1 and $2(F=1.16$, $\mathrm{df}=1 / 21$ ).

The elimination of interspersed test trials significantly improves performance in the confirmation training procedure, at least when the Ss are educable mentally retarded children. The addition of reinforcements by $\mathrm{E}$ (Condition 2) on practice trials only, should have made practice and test trials distinguishable to the Ss. It did not, however, improve performance above that seen in Condition 1 where no reinforcement was given by $E$. In both Conditions 1 and 2 , the $\mathrm{S}$ was positively reinforced for an incorrect response on test trials. Elimination of test trials results in positive reinforcement for correct responses only.

This finding indicates that it will be difficult to directly assess possible differences in performance that might be produced by prompting and confirmation; for if confirmation performance is maximized, then separate test trials must be eliminated. However, as Hawker (1967) observes, separate test trials must always be part of the prompting procedure.

\section{REFERENCES}

COOK, J. O. Supplementary Report: Processes underlying learning in a single paired-associate item. Journal of Experimental Psychology, $1958,56,455$.

COOK, J. O., \& SPITZER, M. E. Supplementary report: Prompting versus Confirmation in paired-associate learning. Journal of Experimental Psychology, 1960, 4, 275-276.

HAWKER, J. R. The effects of prompting and confirmation in a serial learning task. Journal of Experimental Psychology, 1964, 67, 99-101. 
Table 1

Two-Point Thresholds for Five Ss Under Simultaneous and Successive Conditions Millimeters Separation

\begin{tabular}{lrrrrrrr}
\hline & \multicolumn{7}{c}{ Subject } \\
\cline { 2 - 7 } Condition & CJ & RT & PE & TN & JS & $\begin{array}{c}\text { Group } \\
\text { Mean }\end{array}$ \\
\hline Simultaneous & 8.08 & 10.50 & 12.18 & 9.07 & 16.95 & 11.36 \\
Successive & 7.25 & 13.60 & 9.69 & 7.28 & 12.92 & 10.15 \\
\hline
\end{tabular}

was used in both the simultaneous and successive conditions. Results

To determine the two-point threshold from the data, each S's responses were divided into two categories, "zero" and "not zero." The cumulative proportion of "not zero" responses was plotted as a function of stimulus distance.

Under this set of conditions, Ss frequently made "not zero" responses when only one tactor was activated. The proportions of these "false alarm" responses ranged from 0.08 to 0.50 with a median of 0.25 over the five Ss. In order to compare the results with the previous experiment, the threshold proportions were transformed using the "correction for guessing" formula: $p^{\prime}=(p-c) /(1-c)$, where $p^{\prime}$ is the transformed proportion, $p$ is the observed proportion, and $c$ is the proportion of "not zero" responses at the zero stimulus level. The transformed proportion, $\mathrm{p}^{\prime}$, ranges between zero and one, with the threshold defined as that stimulus corresponding to $\mathbf{p}^{\prime}=0.50$.

Cumulative normal probability functions were fitted to the "corrected" threshold data using a probit analysis method with untransformed stimulus values (Finney, 1952). Table 1 gives the obtained thresholds for each $S$ under the two stimulus conditions. Mean threshold over Ss for simultaneous presentation was $11.36 \mathrm{~mm}$, while mean threshold for successive presentation was $10.15 \mathrm{~mm}$. The difference between simultaneous and successive presentations was not statistically significant in the analysis of variance, with the obtained $\mathrm{F}=1.02$.

\section{DISCUSSION}

The two-point threshold distances for simultaneously presented vibratory stimuli are considerably less than those reported for static two-point calipers. In fact, the thresholds approximate those obtained when the caliper points are touched successively, as in the so-called "error of localization" experiment (Boring, 1942). In addition, there was no reduction in thresholds when vibratory stimuli were presented successively.

The results of the experiment were at variance with two-point thresholds for vibration reported by Geldard to be "many times greater" than those for static touch (Geldard, 1961). Differences in the nature of the vibratory stimuli used in Geldard's laboratory and those used in this laboratory may account for the difference in the magnitude of the thresholds obtained. The tactors used in the experiments reported by
Geldard were in constant contact with the skin under $100 \mathrm{~g}$ pressure. Vibration from one tactor, in setting up traveling ripples across the skin, tended to generate false localizations as the ripples moved against other inactive tactors. Since the tactors touched the skin under constant pressure, it is possible that adaptation had reduced sensitivity so that most of the remaining localization sense was derived from deeper tissues (Geldard, 1961).

The failure of these experiments to demonstrate a difference between simultaneous and successive two-point vibratory thresholds indicates that such differences using static stimuli are likely related to the reaction of the cutaneous touch system over time. Inhibitory action of the sort proposed by Békésy (1960), spreading in a wave from the two points of contact might be seen as generating a mutual masking effect on the touch sensations derived from the two points. The touched points could then be sensed as "two" only at a distance beyond the radius of effective inhibitory action. However, two vibrating stimuli presented as discrete "pokes" (as in the action of this laboratory's system) might be of sufficiently short duration that the inhibitory wave could not become fully developed, or would be of smaller magnitude, thus generating its masking effect over a shorter range.

\section{REFERENCES}

BACH-Y-RITA, P., \& COLLINS, C. C. Sensory plasticity and tactile image projection (abstract). Investigative Ophthalmology, 1967, 6, 669.

BÉKÉSY, G. von. Neural inhibitory units of the eye and skin. Quantitative description of contrast phenomena. Journal of the Optical Society of America, 1960, 50, 1060-1070.

BLISS, J. C. Kinesthetic-tactile communications. IRE Transactions, IT-8, 2, February 1962 .

BORING, E. G. Cutaneous sensation after nerve division. Quarterly Journal of Experimental Physiology, 1916, 10, 1-95.

BORING, E. G. Sensation and perception in the history of experimental psychology. New York: Appleton-Century-Crofts, 1942.

COLLINS, C. C. Tactile image projection (abstract). National Symposium on Information Display, 1967, 8, 290.

FINNEY, D. J. Probit analysis. (2nd ed.). Cambridge, England: University Press, 1952.

GELDARD, F. Some neglected possibilities of communication. Science, $1960,135,1583-1588$.

KOTTONKAMP, R., \& ULLRICH, H. Versuche uber den Raumsin der Haut der oberen Extremität, Zeitschrift fur Biologie, 1870, 6, 37-52. MORRIS, A., COLLINS, C. C., \& BACH-Y-RIT A, P. Factors influencing cutaneous sensitivity. Western Psychological Association, San Francisco, May 1967.

VIERORDT, K. Die Abhängigkeit der Ausbildung des Raumsinnes der Haut von den Beweglichkeit der Körpertheile. Zeitschrift für Biologie, $1870,6,53-72$.

WOODWORTH, R. S. Experimental psychology. New York: Henry Holt, 1938.

WOODWORTH, R. S., \& SCHLOSBERG, H. Experimental psychology (Rev. ed.). New York: Holt, Rinehart \& Winston, 1954. NOTES

1. This research was supported by Social and Rehabilitation Service Grant RD-2444-S-C1, NINDB Career Development Award K3 NB14,094 to Dr. Bach-y-Rita, NIH General Research Support Grant FR-05566, and the T. B. Walket Foundation, Inc.

2. Also at San Francisco State College, San Francisco, California.

(Continued from page 145)

HAWKER, J. R. The effects of training procedure, response availability, and response meaningfulness in multiple-choice paired-associate learning. Psychonomic Science, 1965a, 3, 329-330.

HAWKER, J.R. The effects of training procedure, response similarity, and number of response alternatives in multiple-choice paired-associate learning. Psychonomic Science, 1965b, 3, 331-332.

HAWKER, J. R. Training procedure and verbal-discrimination learning by mental retardates. Research Report No. 3, 1966, Austin State School, Behavioral Development Center, Austin, Texas.
HAWKER, J. R. The effects of training procedure and variations in the P-A paradigm on the learning of paired-associations. Psychonomic Science, $1967,7,347-348$.

NOTE

1. This study was supported by the Office of Education Grant No. OEG 0-8-070185-1750. 